\title{
Democracia e saúde: a prestação de contas como legitimadora da representação no Conselho Municipal de Saúde de Vitória (ES)*
}

\author{
Democracy and health: accountability as legitimating of \\ representation in the Municipal Health Council of Vitoria (ES)
}

Marcelo Eliseu Sipioni1, Marta Zorzal e Silva²

RESUMO A participação em conselhos gestores ocorre via representação, mas de forma distinta daquela exercida nos parlamentos. Através da construção do Discurso do Sujeito Coletivo de representantes e representados, buscou-se analisar a representação da sociedade no Conselho Municipal de Saúde de Vitória (ES) a partir da prestação de contas dos representantes. Apesar de alguns discursos demonstrarem distanciamento entre ambos, outros indicam grande proximidade, o que revela certa legitimidade da atividade participativa nestas instâncias. É necessário aprofundar esse debate para que se possa ampliar as possibilidades de um melhor entendimento sobre a representação em instâncias participativas.

PALAVRAS-CHAVE Participação social; Democracia; Conselhos de saúde.

*Este trabalho é fruto da dissertação de mestrado de Marcelo Eliseu Sipioni, intitulada 'Legitimidade da representação em conselhos de saúde: o caso do Conselho Municipal de Saúde de Vitória-ES', defendida junto ao Programa de Pós Graduação em Saúde Coletiva da Universidade Federal do Espírito Santo (PPGSC/Ufes) em setembro de 2009

1 Universidade Vila Velha (UVV) - Villa Velha (ES), Brasil.

mesipioni@yahoo.com.br

2 Universidade Federal do Espírito Santo (Ufes), Departamento de Ciências Sociais, Programa de PósGraduação em Ciências Sociais - Vitória (ES), Brasil. mazorzal@gmail.com
ABSTRACT Participation in management councils occurs by representation, but differently from that exerted in parliaments. Through the building of representatives and represented Collective Subject Discourse, we analyze the representation of civil society in the Municipal Health Council of Vitoria from the accountability of representatives. Despite some speeches demonstrating a distancing between both, others indicate close proximity, which reveals a certain legitimacy of participatory activity in these instances. It is necessary to deepen the debate to expand the possibilities of a better understanding of the representation in participatory instances.

KEYWORDS Social participation; Democracy; Health councils. 


\section{Introdução}

A existência de instituições participativas demandadas, em grande parte, pela pressão popular durante a ditadura militar (19641985) gerou um aumento substancial na participação da sociedade civil na tomada de decisões relativas às políticas públicas. Assim, instituídos legalmente (como os conselhos gestores) ou através de políticas governamentais de partidos de esquerda (no caso dos orçamentos participativos), essas formas institucionais alargaram consideravelmente o pressuposto democrático no Brasil. Isso porque se instaurou um modelo híbrido de democracia (AVRITZER; HOUTZAGER; CASTELLO, 2006) em que representação e participação estão combinadas.

Com a inserção de novos atores em instâncias de tomada de decisões, surgem também novas formas de representação ligadas à sociedade civil. Formas estas que devem ser discutidas e analisadas diferentemente dos enfoques dados à representação parlamentar (AVRITZER, 2007), mesmo porque, é a esta forma eleitoral que se atribui a crise da representação política atualmente (MENDES, 2007).

Na segunda metade do século XX, houve grande reivindicação por participação da sociedade em nome de uma democracia participativa e pouco se pensou no formato em que se consideraria essa participação (LAVALLE; HOUTZAGER; CASTELLO, 2006).

De fato, a democracia representativa reduz ao ato do voto a participação da sociedade, reduzindo também a soberania popular a um procedimento de escolha de governos (SCHUMPETER, 1984). Tal modelo entende que a capacidade de decisão e debate político do povo é baixa, de modo que a sociedade deve limitar-se a autorizar uma elite técnica e qualificada a exercer o papel de gerir a máquina pública.

Alguns autores (PATEMAN, 1992; SANTOS; AVRITZER, 2002), contudo, tentam rebater tais conceitos pregando uma concepção ampliada de democracia, capaz de considerá-la mais que um procedimento para formação de governos: como substância, como forma de liberdade e igualdade de toda uma nação. Segundo as concepções da democracia representativa, jamais seria possível que a pluralidade de atores sociais de uma nação tivesse a oportunidade de vocalizar suas demandas (SANTOS; AVRITZER, 2002). Em suma, a democracia participativa tem como ideia central a autodeterminação política da pluralidade social e prega o reconhecimento dessa pluralidade e a criação de canais em que ela possa ser expressada (FERRAZ, 2006).

Apesar das ideias antagônicas entre essas teorias democráticas, vem-se assumindo uma visão de complementaridade entre ambas (SANTOS, 1999; SANTOS; AVRITZER, 2002; AVRITZER, 2006; FERRAZ, 2006), estabelecendo, assim, a inevitabilidade da representação no interior de experiências de participação (LÜCHMANN, 2007). O que se busca é uma normatização mínima que consiga estabelecer determinados pressupostos para o alcance da legitimidade da representação em instâncias participativas, de forma que os representantes, nesse modelo de representação, possam ser avaliados por seus representados de maneira diferente da que há atualmente na representação em instâncias parlamentares.

Este trabalho é pautado na necessidade de entender a lógica da representação em espaços institucionais de participação e apontar caminhos para que esses mecanismos participativos enriqueçam a democracia e não reproduzam práticas da representação parlamentar. Sendo assim, o objetivo é analisar o formato em que ocorre a representação da sociedade civil no Conselho Municipal de Saúde de Vitória (ES), avaliando sua legitimidade através da prestação de contas dos representantes.

\section{Participação e representação em con- selhos gestores de políticas públicas}

Entre os espaços institucionais para a realização das análises sobre a representação política em instâncias participativas, encontram-se 
os conselhos gestores de políticas públicas. Partiu-se da premissa de que estes conselhos buscam reduzir a distância entre política e senso comum, retirando a exclusividade dos representantes tradicionais em propor estratégias e políticas somente via representação eleitoral (BORBA; LÜCHMANN, 2008).

Entre os diversos conselhos setoriais, os conselhos de saúde parecem ser os mais visados pela literatura. Atualmente, não são raros os trabalhos que se dedicam ao assunto da representação política nesses espaços. A depender dos seus objetivos ou pontos de vista teóricos, alguns se debruçam com maior justificativa e mais densidade do que outros sobre as teorias da democracia e as concepções políticas da participação e da representação. Tais diferenças de abordagem não reduzem a importância de quaisquer trabalhos, de forma que foi possível confirmar a riqueza de literatura que há à disposição para discutir os presentes dados (CORREIA, 2000; LABRA, 2002; LABRA; FIGUEIREDO, 2002; COELHO; VERÍSSIMO, 2004; GERSCHMAN, 2004; DAVID, 2005; GUIZARD; PINHEIRO, 2006; CORTES, 2009; FLEURY; LOBATO, 2009).

Apesar dos reconhecidos avanços, diversas avaliações negativas vêm sendo feitas em relação aos conselhos gestores. Um dos motivos para tal refere-se ao equivocado olhar que a eles normalmente é lançado. Analisar os conselhos gestores sob a perspectiva de ruptura radical com mecanismos tradicionais de representação impossibilita a visão de que a participação nesses espaços não é direta, mas se realiza nos moldes da democracia representativa. Muda-se a relação entre representantes e representados, porém, o tipo de vínculo criado permanece sendo o da representação (FERRAZ, 2009).

Cabe abrir um parêntese importante para que fique claro que os autores aqui trabalhados vêm afirmando uma relação estreita entre representação e democracia, ao contrário de teóricos clássicos radicais, como Rousseau (PITKIN, 1979; 2006; AVRITZER, 2007). Saward (2008), por exemplo, é enfático ao dizer que apenas a representação pode tornar possível a democracia e faz uma crítica a esta mesma representação que, segundo ele, vem substituindo a democracia, e não a servindo. Para esse autor, bem como para Urbinati (2006), a representação não deve ser considerada uma alternativa second best à democracia direta, mas sim deve ser entendida como "um modo de a democracia recriar constantemente a si mesma e se aprimorar" (URBINTATI, 2006; P. 192). A questão central deve ser o entendimento de que a ideia de representação da qual trata este trabalho, que envolve a representação da sociedade civil, mesmo que se baseie em pressupostos da representação em parlamentos, deve criar para si uma teoria própria (URBINTATI, 2006).

O que determinará a legitimidade da representação não é, por si só, o representante e seus laços com a base representada. Ela dependerá também do grau ativo da participação da sociedade civil (LÜCHMANN, 2007), de modo a estabelecerem também entre si uma conexão capaz de efetivar processos legítimos de autorização e prestação de contas durante todo o mandato (YOUNG, 2006; URBINTATI, 2006).

Ao diferenciar e separar representantes e representados, Young (2006) e outros autores (URBINATI, 2006; LÜCHMANN, 2007) procuram responder como se daria o processo de representação ao longo do mandato, apontando para uma resposta que tende a não deixar dúvidas de que uma representação legítima da sociedade civil requer, acima de tudo, uma conexão entre representantes e representados e uma conexão também entre os próprios representados. Caso essas conexões não ocorram, a representação torna-se pouco democrática (YOUNG, 2006).

Parece claro, portanto, que a legitimidade da representação nos espaços representativos da sociedade civil dependerá das posturas tanto do representante quanto dos representados mediante o mandato que exercerá o primeiro.

Tal postura pode ser entendida sob diferentes critérios de análise: perfil socioeconômico dos representantes, a pretensão de legitimidade pelos mesmos, ou seja, os 
sentidos que estes atribuem à representação, e, por fim, os mecanismos de autorização e prestação de contas (BORBA; LÜCHMANN, 2008). Sobre este último debruçou-se esta análise. Um exame teórico mais profundo sobre o tema aqui proposto pode ser encontrado em Sipioni e Silva (2013).

\section{Metodologia}

Considerou-se, primeiramente, a necessidade de se adotar uma abordagem metodológica que permitisse analisar com profundidade os sentimentos, símbolos e representações expressas nas falas dos sujeitos dessa pesquisa. Sendo assim, a abordagem qualitativa é a que melhor se encaixa em uma pesquisa como esta, um estudo de caso de caráter descritivo-exploratório.

O estudo aqui descrito configura parte da pesquisa de mestrado em saúde coletiva realizada pelos autores nos anos de 2008 e 2009, intitulada 'Legitimidade da representação em conselhos de saúde: o caso do Conselho Municipal de Saúde de Vitória-ES', junto ao Programa de Pós-Graduação em Saúde Coletiva da Universidade Federal do Espírito Santo. Assim, os dados foram coletados junto ao Conselho Municipal de Saúde de Vitória (CMS-V) após devida apreciação em plenária de reunião ordinária do órgão, além de ter sido aprovado pelo Comitê de Ética em Pesquisa da Universidade Federal do Espírito Santo, sob o registro 119/08, respeitando todos os princípios éticos com pesquisas envolvendo seres humanos.

A coleta dos dados qualitativos contou com a utilização de entrevistas semiestruturadas direcionadas aos conselheiros representantes da sociedade civil e aos membros da mesa diretora da entidade representada pelo conselheiro. Os roteiros de entrevistas foram adaptados de David (2005) e buscaram evidenciar quesitos básicos sobre o perfil de conselheiros e questões relacionadas à relação entre representantes e suas entidades. Para análise dos dados qualitativos, foi utilizada a técnica do Discurso do Sujeito Coletivo (DSC) (LEFÈVRE; LEFÈVRE, 2003), elaborada com base na teoria das representações sociais. Com o DSC, obtém-se uma resposta coletiva sobre uma determinada opinião comum a diferentes depoimentos. Desta forma, é criado um discurso em primeira pessoa representativa de todos os discursos semelhantes em um conjunto de dados.

Em princípio, todos os conselheiros titulares representantes da sociedade civil e suas respectivas entidades participariam da pesquisa, desde que aceitassem fazê-lo mediante consentimento livre e esclarecido sobre os objetivos da pesquisa.

\section{Resultados e discussão}

Alguns aspectos relevantes de alguma forma limitaram o conteúdo analítico deste trabalho. O primeiro deles refere-se ao difícil acesso a alguns dos representantes. $\mathrm{O}$ objetivo seria entrevistar com profundidade analítica os oito representantes titulares da sociedade civil no conselho. Porém, por questões diversas, foi possível o acesso a apenas quatro. Sendo assim, os quatro conselheiros titulares que não puderam ser entrevistados foram substituídos por outros quatro suplentes, com participação ativa no conselho, entendendo que o teor dos discursos não foi prejudicado por esse fato. As entrevistas foram realizadas entre maio e agosto de 2009.

Em relação às entidades, buscou-se entrevistar os dirigentes daquelas cujo representante no CMS- $\mathrm{V}$ havia participado das entrevistas, gerando um total de cinco entidades. Destas, uma não pôde participar da pesquisa por afirmar que a única pessoa capaz de responder pela entidade seria a própria conselheira, o que enviesaria sobremaneira a análise deste trabalho.

O CMS-V possuía, no momento da pesquisa, 16 membros representantes da sociedade civil (8 titulares e 8 suplentes), sendo que as outras 16 vagas são divididas entre 
profissionais de saúde do Sistema Único de Saúde (SUS) e gestores (BRASIL, 2003).

Por questões de limitação de espaço, não foram aqui transcritos todos os DSC representativos das diversas ideias centrais. Assim, buscamos explicitá-las durante nossas discussões.

Procuramos observar, primeiramente, a quem os representantes buscam representar no CMS-V, de forma que os DSC passaram a ideia de representação generalizada, no sentido de substituir o Estado, e também de afirmação de representação da entidade enquanto representantes de um grupo específico.

Em outro enfoque, procurou-se analisar a relação prática dessa representação. Em termos gerais, observou-se como tem ocorrido o diálogo entre representantes e entidade representada, observando regularidade ou não de relatórios, discussão prévia das pautas com os membros da entidade, entre outras situações de accountability.

Outra abordagem que visou elucidar a questão da prestação de contas refere-se à qualificação do representante. Dessa forma, também as entidades foram analisadas para saber se há ou não qualificação por parte destas para possuírem cadeira no CMS-V.

\section{A quem representar?}

\section{VISÃO GENERALIZANTE}

Ao analisar as falas que revelam os interesses representados, notou-se que o interesse dos representantes pode ser visto como um interesse geral, enfatizando o bem de toda a população. Nesse sentido, no DSC a seguir observa-se que o objetivo prioritário de alguns entrevistados abrange um papel amplo de agente social promotor de igualdade, tomando para si um papel que, em princípio, deveria ser do Estado.

É o bem-estar da população. O meu objetivo é levar e trazer informação pra minha comunidade. $E$ tá buscando a questão da necessidade, tá lutando praquilo de direito mesmo. Direito de igualdade.
Fazer com que as coisas aconteçam com transparência. Sempre tá querendo saber cada vez mais pra levar até eles. E eles, na comunidade, têm o conhecimento por intermédio da minha pessoa. $E$ eu vejo que minha comunidade precisa demais da minha ação, sendo a voz daqueles que não têm voz. (DSC - Representantes dos usuários; proporção $4 / 8$ ou $50 \%$ ).

Sob essa ótica, Abers e Keck (2008) fazem uma interessante discussão ao ressaltarem que nos conselhos gestores há também cadeiras destinadas a representantes indicados pelo poder público. Dessa forma, por mais que o discurso das organizações civis remeta a uma ideia de justiça social, elas não têm obrigações, necessariamente, para com toda a população. Ao contrário, os indicados do poder público é que devem ser responsabilizados pela falha dos conselhos em não promover a defesa efetiva dos interesses dos não organizados. Tal responsabilização se dá pelo fato de que, por natureza, os representantes do Estado têm obrigações para com toda a sociedade, e devem representar os interesses de todos.

\section{VISÃO RESTRITA À REPRESENTAC̣ÃO DA ENTIDADE}

Algumas falas, por sua vez, menos numerosas direcionam as análises para uma visão mais focada de representação em que se assume o papel do representante como aquele que representa a vontade da entidade, como se vê a seguir.

[O papel do representante] é falar pela entidade. É lutar pela entidade. É ter o compromisso pela entidade, e não por você mesma. É priorizando as demandas da sua entidade. Passando informações, os informes do que tá acontecendo em volta. A importância é isso, é dar o retorno, dar o feedback. Porque ali é o espaço das comunidades, da sociedade organizada. E as coisas são camufladas demais... Então ali o meu papel é estar falando pela minha entidade, que eu represento. 
E não por mim mesma, levando coisa que não seja pelo coletivo. (DSC - Representante dos usuários; proporção 2/8 ou 25\%).

Nas análises dos DSC das entidades, algumas falas também mostraram que esse ideal de representação política ocorre não somente nos representantes, mas naqueles que são representados.

Ele não pode se representar. Ele tem que representar a entidade do qual ele foi indicado. Porque ninguém pode sentir nada por nós. Somos nós que vivemos o preconceito, a discriminação, o deboche... Somos nós que somos marginalizados. 0 nosso representante tá respaldado pra participar. Então, o que é bom para o povo, o que é bom para o coletivo, tem que, obrigatoriamente, ser bom para a entidade. (DSC - Membros de entidade representada; proporção 2/4 ou 50\%).

Essa visão parece captar de forma mais abrangente o ideário dessa nova forma de representação política. Porém, deve-se observar de maneira crítica as colocações desse discurso para saber se não vem se firmando nessa relação uma noção meramente identitária de representação.

Como lembra Young (2006), a premissa básica da representação política é compreender que o ato de representar não admite uma relação de identidade entre representantes e representados devido à realidade irrefutável de que os primeiros não conseguirão em todos os momentos falar em nome de todos os representados, subentendendo, portanto, a expressão da vontade de todos. É inerente a essa relação que representantes e representados sejam diferentes e que imaginar a abrangência de todas as opiniões na voz de um só é utópico e impossível de ser concretizado.

\section{Como representar?}

Vários são os DSC que possibilitam uma análise de prestação de contas caracterizada como difusa entre representantes e representados. Alguns assumiram não discutir, até mesmo pela pouca estruturação de sua entidade. Outros afirmaram que, sistematicamente, põem em pauta os assuntos discutidos no CMS-V, tanto levando demandas para o conselho como trazendo decisões a serem tomadas na entidade.

\section{ELABORAC̄ÃO DAS PROPOSTAS A SEREM DISCUTIDAS NO CMS-V}

Os discursos que se seguem reúnem falas que mostram em seu conteúdo uma dificuldade ou ausência de reunião com a entidade para discutir propostas a serem levadas ao conselho, o que resulta em uma demonstração implícita da pouca frequência com que o representante consulta sua base para discutir propostas no conselho ou mesmo uma subestimação do espaço e opinião da entidade para assuntos 'não sérios', como descrito abaixo.

Nem todas [as pautas] a gente tá lendo. A gente costuma se reunir com eles quando tem uma coisa muito séria pra passar, né? E quando a gente tem oportunidade, a gente tá sempre discutindo, passando o que é saúde, o que é discutido aqui, o que está ali. Se você confia aquela pessoa a esse conselho, caso tiver alguma coisa muito difícil a gente tem que se reunir, mas no dia a dia a gente tem abertura... Nem sempre a gente precisa de ir lá [na entidade] porque as coisas que é pra deliberar aqui [no conselho]... A gente já tem tanto tempo que tá aqui, que já conhece esse caminho. Mas quando é necessário a gente vai sim. (DSC - Representante dos usuários; proporção $3 / 8$ ou $37,5 \%$ ).

Os argumentos para essa autonomia do representante perante a entidade são diversos, como se pode notar acima. Subestimação da opinião dos seus membros e entendimento de que sua experiência como conselheiro lhe dá respaldo para tal autonomia conferem subsídios para afirmar que a cultura política tradicional, que sugere a existência do político profissional, ainda alicerça a atuação desses novos representantes. Ao mesmo 
tempo, reafirma que falta a eles uma qualificação técnica e política capaz de subsidiar sua participação.

\section{QUALIFICAC̣ÃO}

É notório, segundo o DSC a seguir, que há, por parte dos conselheiros sem nível superior, um descontentamento pela disputa entre os saberes técnico e popular, mais efetivamente, entre representantes dos usuários em relação aos profissionais da saúde e gestores.

O desafio [de representar a minha entidade no conselho de saúde], às vezes, é dos próprios conselheiros. Desafio de inveja, de repúdio por pensarem diferente, às vezes, por visões diferentes, entendeu? Porque você vê que tem muita gente ali, os gestores, tem médicos, e eu não tenho faculdade, eu tenho a faculdade da vida, mas eu sou muito inteligente, entendeu? Que nós não temos uma capacitação de entendimento na saúde. Não tem uma pessoa que tem esse conhecimento na área da saúde. Então é um desafio vir pra cá sem esse conhecimento. Mas eu não me intimido. Eu brigo pelos direitos da população, eu enfrento. Quer ficar com raiva de mim? Fica! [...] Então, o desafio, é a visão de cada conselheiro. (DSC - Representante dos usuários; proporção 4/8 ou 50\%).

Vários estudos vêm demonstrando essa desqualificação, como em Gerschman (2004) e Tatagiba (2002). O fato é que as desigualdades existentes no meio sociopolítico, geradores de diferenças entre saberes, restringem a participação política e, consequentemente, acentuam ainda mais a desigualdade, acarretando um processo de exclusão (COELHO, 2007). Lüchmann (2002) ressalta os problemas não só da desqualificação do conselheiro, mas também da falta de capacitação e informação como limitantes de sua atuação em relação aos representantes da sociedade civil e àqueles conselheiros possuidores de elevado grau de escolaridade.
Constatou-se neste trabalho que as entidades extremamente desarticuladas, que nem sequer possuíam um corpo diretor capaz de participar desta pesquisa sem enviesá-la, e as entidades que só aceitaram enviar seu representante depois de anos consecutivos de convites por parte da secretaria municipal de saúde - e que não possuem atuação ou influência na área da saúde ou mesmo não priorizam a questão da saúde em suas ações - compõem o segmento dos usuários no CMS-V.

Em contrapartida, notou-se que estes dados não podem ser generalizados por não se referirem a todas as entidades representadas. Algumas falas permitiram criar um discurso coletivo que revelou algumas entidades que realizam ações e atividades específicas para a área da saúde, fato que se considera ser de decisiva importância para sua atuação conselhista, já que defendem posições mais enraizadas nos problemas vividos pela sua própria ação comunitária. É uma pena, contudo, que essa não seja uma realidade de todas as entidades.

\section{PAUTAS E RELATÓRIOS}

Prosseguindo nas análises deste trabalho, observou-se que um problema recorrente na literatura (TATAGIBA, 2002; VAN STRALEN ET AL., 2006) foi citado em um dos discursos: o envio da pauta pela secretaria da mesa diretora do CMS-V é feito com pouco prazo para que haja tempo de os representantes se reunirem com a entidade para discutir os assuntos que nortearão a reunião seguinte. $\mathrm{O}$ fato é que o envio prévio da pauta é importante não só para a obtenção de tempo hábil para o diálogo com a base representada como também para o amadurecimento do próprio conselheiro sobre a ideia a ser discutida no conselho (TATAGIBA, 2002).

Referente a essa análise, sob o ponto de vista das entidades, notou-se que também houve discursos que salientaram esse 
referido distanciamento entre entidade representada e representante no CMS-V. Questionando se há informações ou discussões a respeito da pauta do conselho por parte do representante de entidade, obteve-se o DSC a seguir:

Não. Pouco. Muito pouco. Isso aí nós falhamos. Inclusive, é uma demanda, uma coisa que nós estamos percebendo agora. Inclusive ela, como representante, o diálogo tem sido pequeno, no nosso entender. Precisa ser intensificado, até pra gente poder fazer também, tudo isso que é observado no trabalho do dia a dia, chegar no conselho, que é a instância que vai, realmente, articular essa política, né. Porque não existe uma relação de relatório. A gente já até pediu, relatório pra trazer, e tal, mas estamos realmente com dificuldades desse representante enviar relatórios. (DSC - Membros de entidade representada; proporção $2 / 5$ ou $50 \%$ ).

Também não ocorrem os repasses de todas as reuniões realizadas à base, como relatado em alguns discursos, permitindo concluir que não há feedback dos conselheiros para suas entidades referentes à pauta de discussão do CMS-V.

Para entender como, então, essas entidades definem suas posições para serem levadas pelo representante ao conselho, é necessário a análise do DSC a seguir.

Sistematização [da pauta do CMS-V] não existe. Existe, a bem da verdade, é a discussão. É a constatação. Isso existe. Mas assim, no momento, a dinâmica do nosso trabalho ainda não levou a essa perfeição, ainda não levou a esse... o que seria assim, o ideal de ser construído, né. Muito embora a gente discuta, muito embora se saiba quais são as dificuldades, se sabe até alguns caminhos pra se chegar, mas na verdade ainda não se chegou a sistematizar e de utilizar o conselho de saúde ainda nessa forma propositiva, de forma que viéssemos a ajudar. (DSC - Membros de entidade representada; proporção $2 / 4$ ou $50 \%$ ).
Um ponto extremamente importante no processo de prestação de contas vem sendo negligenciado pelos representantes, conforme constatado em discurso dos membros de entidade: a apresentação de relatório à entidade representada. Acredita-se que o relatório possui importância fundamental por ser uma maneira de formalizar uma relação de representação e também de documentar e tornar público o acesso dos membros da entidade a essas informações. Seria uma forma de manter contínua e sistematizada a troca de informações entre representantes e representados.

Nas entidades em que os representantes não produzem o relatório, seus diretores/ presidentes demonstram em suas falas que esse seria um interessante mecanismo de fiscalização da representação, mas que não vem sendo cumprido pelo representante, o que reforça a ideia de uma postura independente e autônoma do conselheiro em relação à base representada. Com isso, os representados não sabem como anda a atividade conselhista de seu representante.

A ausência de relatório torna-se argumento para muitas 'faltas' das entidades na relação entre a entidade representada e o representante. Uma delas diz respeito à ausência de suporte (técnico, financeiro, político), que seria facilitado se a entidade soubesse mais sobre a atuação de seu representante. Além disso, delega-se ao poder executivo a premissa de qualificar seus conselheiros no conselho em detrimento do suporte da entidade, como se observa no DSC a seguir.

Não, não temos [suporte para os nossos representantes]. Ainda não. Isso é muito importante colocar. Que é o ideal ter, dar uma estrutura. Mas isso precisa fazer o relatório pra poder socializar, fazer o acompanhamento amplo da entidade, como tá atuando. Mas a gente pede para que a própria administração e a secretaria façam cursos específicos para as pessoas, para 'empoderar'. Mas assim, a gente apoia, a gente debate, discute. Então, a gente dá condição. 
Ele leva muito. Alguma coisa que ele tem dúvida, ele leva pro grupo. (DSC - Membros de entidade representada; proporção 4/4 ou 100\%).

Outra consequência negativa da falta de relatório do representante, de acordo com membros das entidades, é a pouca ou inexistente frequência de reuniões com o representante.

Notou-se que as entidades entendem a importância do relatório, culpam seus representantes por não apresentá-los, mas não demonstram rigor na cobrança com punições possíveis. Tal atitude, a de punir quem não apresenta o relatório, torna-se, inclusive, inviável nas entidades que não possuem disponibilidade de pessoas para representação em conselhos gestores e mesmo nas quais a escolha do representante atual se deu após muita insistência, tanto por parte da secretaria de saúde quanto por parte da própria presidência da entidade, de forma que se a punição fosse a retirada do membro da entidade do papel de representante, não haveria ninguém para substituí-lo.

É de se esperar, portanto, que as entidades civis reúnam-se ordinariamente para debaterem suas demandas e atividades, de modo que a atuação nos conselhos gestores tome forma como ponto de pauta nessas reuniões, como acontece em algumas entidades entrevistadas. Ou seja, a participação da entidade em conselhos gestores não pressupõe, necessariamente, motivação única de reuniões específicas, a não ser que seja realmente indispensável, quando se tratar de um assunto relacionado ao conselho e que seja de extrema relevância para a entidade.

Algumas falas analisadas mostraram que esses mecanismos de prestação de contas não ocorrem por diversos motivos: falta de interesse do representante, falta de cobrança da entidade, falta de apoio da mesa diretora do conselho, entre outros. É evidente que esses entraves podem ser evitados, cabendo a cada um cumprir seu papel para que se inaugure uma cultura de representação que leve em conta mecanismos formais de prestação de contas. A legitimidade dessa representação viria por consequência.

Alguns fragmentos das diversas falas apresentadas e discutidas até aqui remetem à conclusão da existência de uma concepção fiduciária de representação no seio da sociedade civil participante do CMS-V, o que também foi encontrado em outros estudos (LABRA, 2002; DAVID, 2005; BORBA; LÜCHMANN, 2008).

A representação fiduciária (BOBBIO, 2000) indica uma autonomia do representante em relação à sua base que, para este tipo de formato representativo presente nos conselhos gestores, não seria ideal, encaixando-se mais em uma concepção parlamentar de representação política em que a relação dá-se por confiança dos representados para com seu representante, sem presença sistemática de prestação de contas, sendo essa concepção compatível com o ideal de democracia representativa, não participativa. É válido, pois, pensar que, quanto mais distante possível da visão fiduciária de representação nos conselhos gestores, melhor será o entendimento democrático desta relação.

\section{A APROXIMAC̣ÃO ENTRE REPRESENTANTE E ENTIDADE}

Serão analisados agora alguns discursos que afirmam a necessidade de discussão prévia com a entidade para as proposições no conselho, demonstrando o respeito e a responsabilidade em falar em nome de outrem que alguns conselheiros possuem, distanciando-se, portanto, da visão fiduciária e aproximando-se de uma visão delegativa de representação.

Óbvio! Discuto [a pauta com minha entidade]. Tem que discutir o que eu quero pro grupo. Sem dúvida. É obrigado a prestar todo o relatório das demandas que foram tiradas no conselho. Porque se não discutirmos internamente, nós não podemos levar nada pra lá [CMS-V]. Então, discutimos, brigamos, mas chegamos a um acordo 
definitivo. (DSC - Representante dos usuários; proporção $6 / 8$ ou $75 \%$ ).

Assim como entre os representantes, membros das entidades evidenciaram que a relação com seu representante no CMS-V deve ser constituída sob moldes mais aproximativos, gerando uma noção de responsabilidade coletiva sobre o ato de representar, tanto levando suas posições ao conselho de saúde como informando à entidade as deliberações tomadas lá.

[As deliberações do conselho são passadas] através do nosso representante. Então ele passa, comenta o que aconteceu, discute o posicionamento que teve, tudo nas nossas reuniões. Caso ele precise, a gente se reúne, a gente marca reunião extra, convoca. A gente vai, discute e leva nossa posição. O grupo concorda, o grupo não concorda, o grupo dá diretriz [...] o grupo, então, mostra caminhos. Comentam na reunião e discutem. (DSC - Membros de entidade representada; proporção $2 / 4$ ou 50\%).

Parece que há um avanço considerável dessas falas coletivas em relação às anteriores, tanto pelo conteúdo quanto pela proporção de sujeitos que indicaram essa ideia central no teor de suas falas, especialmente em relação aos representantes no conselho. A prestação de contas durante todo o mandato é um dos principais argumentos de Young (2006) para se efetivar a real representatividade das minorias.

Em pergunta semelhante, a tentativa agora é obter informações a respeito do fato de o representante trazer para a entidade informações sobre suas ações no conselho, bem como as discussões que norteiam suas pautas. Os resultados não foram diferentes dos relatados anteriormente em termos de conteúdo, mas proporcionalmente mostraram-se ambíguos.

Dois discursos, constituídos por ideias centrais de dois sujeitos diferentes, mostram que ou não há prestação de contas ou ainda não houve prestação de contas. Por outro lado, uma maioria dos entrevistados disse haver prestação de contas de suas atividades no CMS-V para a entidade, o que corrobora algumas análises feitas anteriormente.

Sim. Com certeza. Tenho [que prestar contas], né? Sou obrigada. Quando a gente tá à frente da comunidade, a gente tem que fazer esse papel. Então, lá na reunião eu falo tudo que tá acontecendo. Tudo que eu faço na saúde eu tenho que falar 'olha, tá acontecendo isso e isso na saúde e tal'. Inclusive agora, através de relatórios. (DSC - Representante dos usuários; proporção $6 / 8$ ou $75 \%$ ).

Questionados sobre como acontecia essa prestação de contas, algumas ideias compuseram um discurso otimista em que a sistematização desta prestação faz-se presente.

Sempre depois do conselho tem uma reunião. Então, isso tudo eu passo pras pessoas que precisam. Aí eles fazem um relatoriozinho, trago a Ata. Você recebe a Ata de tudo que tá se passando lá dentro, o que você aprovou, o que você não aprovou. Então, fazemos relatórios. Não sei se você notou. Todo mundo lá presta atenção. Eu sempre tô escrevendo alguma coisa, entendeu? É tipo uma prestação de contas. E essa prestação de contas, às vezes, nem é direcionada só ali dentro da entidade. Nós fazemos as reuniões ampliadas e apresentamos. Porque você é um conselheiro, você tem que ser o leva e trás. Eu tenho que pegar aqui e colocar não só para aquele que eu represento, mas também passar pra comunidade. (DSC - Representante dos usuários; proporção $5 / 8$ ou $62,5 \%$ ).

Cabe lembrar que a prestação de contas, como lembra Young (2006), deve acontecer tanto na articulação da entidade/base com seus representantes como também entre os próprios membros da base representada. Sendo assim, se a base está desarticulada ou se seus membros não possuem união para reivindicar atitudes específicas de 
seu representante, este se tornará cada vez mais autônomo e independente para tomar decisões.

\section{Considerações finais}

A representação política, referendada aqui em um novo formato institucional que privilegia a representação nos espaços de participação, é uma forte aliada à ampliação da democracia. O Brasil apresenta referências importantes no que concerne aos espaços participativos, cujas práticas de participação revelam seu caráter representativo.

As observações aqui realizadas buscaram compreender o formato em que se dão essas relações. Discursos ambíguos no mesmo corpo de conselheiros lançaram ainda mais dúvidas ao tema, o que inspira a necessidade de aprofundar esse debate.

É possível que a cultura política do povo brasileiro esteja influenciando o papel das entidades civis no processo representativo em canais participativos, como os conselhos gestores. Essa cultura política, que vem sendo

\section{Referências}

ABERS, R. N.; KECK, M. E. Representando a diversidade: Estado, sociedade e "relações fecundas" nos conselhos gestores. Caderno CRH, Salvador, v. 21, n. 52, p. 99-112, 2008.

AVRITZER, L. Reforma política e participação no Brasil. In: AVRITZER, L; ANASTÁSIA, F. (Org.). Reforma política no Brasil. Belo Horizonte: Ed. UFMG, 2006, p. 35-43.

Sociedade civil, instituições participativas e representação: da autorização à legitimação da ação. Dados, Rio de Janeiro, v.5 0, n. 3, p. 443-464, 2007.

BOBBIO, N. O futuro da democracia. 10. ed. São Paulo: Paz e Terra, 2000. alterada pelo próprio exercício democrático, caracteriza-se por um descrédito da sociedade civil em relação ao poder de mudança dessas instituições participativas, além de encarnar, ainda, relações clientelistas e paternalistas inerentes à política tradicional.

Os resultados deste trabalho apontaram práticas de relação entre representantes e representados que ora reforçam um novo ideal representativo, ora o enfraquecem. Entendese que muitos conselheiros e membros de entidades apresentam em seus discursos falas progressistas quanto ao modo de representar, mas, na prática, a relação, muitas vezes, vem acompanhada do tradicionalismo parlamentar.

Faz-se clara a necessidade de afirmação dos achados positivos dessas análises para que tais práticas possam ser cada vez mais copiadas e discutidas no interior das relações representativas da sociedade civil, desconstruindo a ideia de uma postura de distanciamento para com a base e construindo, por parte do representante, uma outra postura, de aproximação e responsabilidade perante aqueles que representa.
BORBA, J.; LÜCHMANN, L. H. H. A representação política nos Conselhos Gestores de Políticas Públicas In: Congreso Latinoamericano de Ciencia Política, 7., 2008. Anais..., San José: Universidad de Costa Rica, 2008.

BRASIL. Ministério da Saúde. Conselho Nacional de Saúde. Resolução n. 333 de 04 de novembro de 2003. Aprova as diretrizes para criação, reformulação, estruturação e funcionamento dos Conselhos de Saúde. Diário Oficial [da] União. Brasília, DF: Ministério da Saúde, 2003.

COELHO, V. S. P. A democratização dos conselhos de saúde: o paradoxo de atrair não aliados. Novos estud. CEBRAP, São Paulo, n. 78, p. 77-92, 2007. 
COELHO, V. S. P.; VERÍSSIMO, J. Considerações sobre o processo de escolha dos representantes da sociedade civil nos conselhos de saúde de São Paulo. In: AVRITZER, L. (Org.). A participação em São Paulo. São Paulo: Ed. UNESP, 2004, p. 105-122.

CORREIA, M. V. C. Que controle social? Os conselhos de saúde como instrumento. Rio de Janeiro: Ed. Fiocruz, 2000.

CORTES, S. V. Participação e Saúde no Brasil. Rio de Janeiro: Ed. Fiocruz, 2009.

DAVID, C. T. N. Representantes e representados: relação entre conselheiros usuários, suas entidades e espaços descentralizados do Conselho Municipal de Saúde de Porto Alegre. 2005. 151 f. Dissertação (Mestrado em Sociologia) - Universidade Federal do Rio Grande do Sul, Porto Alegre, 2005.

FERRAZ, A. T. R. Cenários da participação política no Brasil: os conselhos gestores de políticas públicas. In: SILVA, M. Z.; BRITO JUNIOR, B. T. (Org.). Participação social na gestão pública: olhares sobre as experiências de Vitória-ES. São Paulo: Annablume, 2009, p. 194-206.

Pensando a democracia e seu processo de adjetivação. Agália, Santa Clara, n. 85-86, p. 173-200, 2006.

FLEURY, S.; LOBATO, L. V. C. (Org.). Participação, democracia e saúde. Rio de Janeiro: Cebes, 2009.

GERSCHMAN, S. Conselhos Municipais de Saúde: atuação e representação das comunidades populares. Cad. Saúde Pública, Rio de Janeiro, v. 20, n. 6, p. 16701681, 2004.

GUIZARDI, F. L.; PINHEIRO, R. Dilemas culturais, sociais e políticos da participação dos movimentos sociais nos conselhos de saúde. Ciênc. Saúde Colet., Rio de Janeiro, v. 11, n. 3, p. 797-805, 2006.

LABRA, M. E. A qualidade da representação dos usuários nos Conselhos Distritais de Saúde do Rio de Janeiro e a dimensão associativa. Relatório Final de Pesquisa Estratégica. Rio de Janeiro: Fundação
Oswaldo Cruz, 2002.

LABRA, M.E.; FIGUEIREDO, J. S. A. Associativismo, participação e cultura cívica: o potencial dos conselhos de saúde. Ciênc. Saúde Colet., Rio de Janeiro, v. 7, n. 3, p. 537-547, 2002.

LAVALLE, A. G.; HOUTZAGER, P. P.; CASTELLO, G. Representação política e organizações civis: novas instâncias de mediação e os desafios da legitimidade. Rev. Bras. Ci. Soc., São Paulo, v. 21, n. 60, p. 43-66, 2006.

LEFÈVRE, F.; LEFÈVRE, A. M. C. (Org.). O discurso do sujeito coletivo: um novo enfoque em pesquisa qualitativa (desdobramentos). Caxias do Sul: Educs, 2003.

LÜCHMANN, L. H. H. A representação no interior das experiências de participação. Lua Nova, São Paulo, n. 70, p. 139-170, 2007.

Os conselhos gestores de políticas públicas: desafios do desenho institucional. Revista Ciências Sociais Unisinos, São Leopoldo, v. 38, n. 161, p. 43-79, 2002.

MENDES, C. V. R. Representação política e participação: reflexões sobre o déficit democrático. Katálisys, Santa Catarina, v. 10, n. 2, p. 143-153, 2007.

PATEMAN, C. Participação e teoria democrática. São Paulo: Paz e Terra, 1992.

PITKIN, H. F. O conceito de representação. In: CARDOSO, F. H.; MARTINS, C. E. (Ed.). Política e Sociedade. São Paulo: Nacional, 1979.

Representação: palavras, instituições e ideias. Lua Nova, São Paulo, n. 67, p. 15-47, 2006.

SANTOS, B. S. Pela mão de Alice: o social e o político na pós-modernidade. São Paulo: Ed. Cortez, 1999.

SANTOS, B. S.; AVRITZER, L. Para ampliar o cânone democrático. In: SANTOS, B. S. (Org.). Democratizar a democracia: os caminhos da democracia participativa. Rio de Janeiro: Civilização Brasileira, 2002.

SAWARD, M. Representation and democracy: revisions 
and possibilities. Sociology Compass, New York, v. 2, n. 3, p. 1000-1013, 2008.

SCHUMPETER, J. Capitalismo, socialismo e democracia. Rio de Janeiro: Fundo da Cultura, 1984.

SIPIONI, M. E.; SILVA, M. Z. Reflexões e interpretações sobre a participação e a representação em conselhos gestores de políticas públicas. Rev Sociologia e Política, Curitiba, v. 21, n. 46, p.147-158, 2013.

TATAGIBA, L. Os conselhos gestores e a democratização das políticas públicas no Brasil. In: DAGNINO, E. (Org.). Sociedade civil e espaços públicos no Brasil. São Paulo: Paz e Terra; Campinas: Unicamp, 2002, p. 47-105.
URBINATI, N. O que torna a representação democrática? Lua Nova, São Paulo, n. 67, p. 191-228, 2006.

VAN STRALEN, C. J. et al. Conselhos de Saúde: efetividade do controle social em municípios de Goiás e Mato Grosso do Sul. Ciên. Saúde Colet., Rio de Janeiro, v. 11, n. 3, p. 621-632, 2006.

YOUNG, I. M. Representação política, identidade e minorias. Lua Nova, São Paulo, n. 67, p. 139-190, 2006.

Recebido para publicação em setembro de 2014

Versão final em outubro de 2014

Conflito de interesse: inexistente

Suporte financeiro: não houve 